\title{
EXPANSÃO E DISJUNÇÃO PALATINA EM PACIENTES CLASSE III COM USO DE MÁSCARA FACIAL
}

\author{
Katia Maria de Lima SUASSUNA ${ }^{1}$ \\ Denis Clay Lopes SANTOS² \\ Daniel NEGRETE ${ }^{3}$ \\ Everton FLAIBAN ${ }^{4}$ \\ Raquel Lopes dos SANTOS 5 \\ Renata BORTOLIN ${ }^{6}$
}

\section{RESUMO}

O tratamento de má oclusão Classe III esquelética representa um grande desafio ao profissional. Quando a má oclusão de Classe III for determinada por uma retrusão maxilar, o tratamento ortopédico precoce é indicado, onde o tratamento de escolha é a disjunção palatina seguida do uso de máscaras faciais. O objetivo deste estudo é analisar e discutir fatores determinantes para o planejamento da expansão maxilar. A metodologia utilizada foi de uma pesquisa bibliográfica, realizada na base de dados da SCIELO e LILACS. Os resultados mostraram que os fatores determinantes para o planejamento da expansão maxilar dependerão do tempo do tratamento para se conseguirem resultados positivos, pois, variam muito, de acordo com as características da força empregada, tais como magnitude, direção e horas de uso; e as chances relação dos maxilares com o crânio, a dimensão vertical e a idade do paciente. Conclui-se que o uso da expansão rápida da maxila ou disjunção palatina associado à máscara facial é bastante eficaz no tratamento da má oclusão de Classe III em idade precoce.

DESCRITORES: MÁ OCLUSÃO DE ANGLE CASSE III; MÁSCARAS FACIAIS; TÉCNICA DE EXPANSÃO PALATINA.

1 Cirurgiã-Dentista, Especialista em Implante e Pós-Graduanda do curso de Ortodontia da Universidade Cruzeiro do Sul

2 Doutorado e Mestrado pela FCM/Unicamp. PHD em Ortodontia e Ortopedia Facial. PHD em Implantodontia. Coordenador do curso de Odontologia da Universidade Cruzeiro do Sul.

3 Mestre em Ortodontia e professor dos cursos de pós-graduação em Ortodontia da Universidade Cruzeiro do Sul

4 Mestre em Ortodontia e professor dos cursos de pós-graduação em Ortodontia da Universidade Cruzeiro do Sul

5 Especialista em Ortodontia, fisioterapeuta e professora dos cursos de pós-graduação em Ortodontia da Universidade Cruzeiro do Sul

6 Especialista em Ortodontia e professora dos cursos de pós-graduação em Ortodontia da Universidade Cruzeiro do Sul 


\section{PALATIN EXPANSION AND DISJUNCTION IN CLASS III PATIENTS WITH FACIAL MASK}

\section{ABSTRACT}

The treatment of skeletal Class III malocclusion presents a great challenge to the professional. When Class III malocclusion is determined by maxillary retrusion, early orthopedic treatment is indicated where the treatment of choice is palatal disjunction followed by facial masks. The purpose of this study is to analyze and discuss determinant factors for maxillary expansion planning. The methodology used was a bibliographic research, carried out in the database of SCIELO and LILACS. The results showed that the determinant factors for the planning of the maxillary expansion will depend on the time of the treatment in order to obtain positive results, since it varies greatly according to the characteristics of the force employed, such as magnitude, direction and hours of use, and the chances of success depend on some factors, such as: the relationship between the maxilla and the mandible, the relation of the jaws to the skull, the vertical dimension and the age of the patient. It is concluded that the use of rapid maxillary expansion or palatine disjunction associated with facial mask is very effective in the treatment of Class III malocclusion at an early age.

DESCRIPTORS: MALOCCLUSION, ANGLE CLASS III; FACIAL MASKS; PALATAL EXPANSION TECHNIQUE.

\section{INTRODUÇÃO}

O tratamento de má oclusão Classe III esquelética representa um grande desafio ao profissional em razão do crescimento potencialmente desfavorável e da imprevisibilidade de resultados estáveis e estéticos'.

As más oclusões da Classe III de Angle definem-se por uma relação sagital entre os arcos dentários, na qual a arcada dentária inferior oclui mesialmente à superior. É considerada complexa devido ao envolvimento das estruturas esqueléticas, dentárias ou uma combinação de ambas, podendo ter comprometimento no sentindo transversal².

O padrão de crescimento individual é influenciado por heranças genéticas, que contribuem para a determinação de maior ou menor discrepância sagital entre as bases. Dessa forma, a má posição dentária poderia ser compensada naturalmente, pelo crescimento ou por tratamento ortodôntico ou pela realização de procedimentos cirúrgicos, dependendo da severidade da má oclusão³.

Alterações no padrão de mastigação são observadas em indivíduos com má oclusão de Classe III, independentemente do tipo facial, o que resulta em movimentos verticais da mandíbula com intensa participação do dorso da língua durante o esmagamento do alimento, pois os movimentos laterais e rotatórios da mandíbula se tornam mais difíceis ${ }^{4}$.

O diagnóstico preciso é fundamental para a escolha da terapêutica mais adequada para cada caso, de forma individual. 0 equilíbrio e a harmonia facial, assim como a oclusão ideal, devem ser objetivos simultâneos e igualmente importantes quando da opção do tratamento ortodôntico. Os achados do exame clínico e a análise do perfil facial devem sempre prevalecer quando comparados aos achados cefalométricos, às análises de modelos de estudo e de fotografias, uma vez que estes são considerados meios auxiliares de diagnóstico ${ }^{4}$.

O sucesso em longo prazo do tratamento da má oclusão de classe III pela expansão maxilar e terapia da protração está associado ao seu início antes do surto de crescimento puberal. Pacientes tratados em fase 
ISSN 1983-5183

de crescimento apresentam melhores resultados quanto às mecânicas empregadas, se comparados com aqueles que apresentam maturidade esquelética. Após a fase de crescimento, há mais limitações para o tratamento ortodôntico e muitas vezes necessidade de correção cirúrgica ${ }^{5}$.

O tratamento das más oclusões esqueléticas Classe III realizado exclusivamente por terapêuticas ortodônticas intrabucais é difícil de ser realizado. Para tanto, forças extrabucais de tração reversa são indicadas como auxiliares às terapêuticas intrabucais nas fases de dentição decídua e mista a fim de evitar cirurgias na idade adulta 5 .

Para a correção de anormalidades como a retrusão de maxila, as deformidades craniofaciais associadas à deficiência maxilar, a combinação entre hipoplasia maxilar e o prognatismo mandibular, o tratamento não cirúrgico mais indicado é o uso da máscara facial, que proporciona resultados favoráveis, principalmente em relação aos aspectos estéticos. Essa abordagem terapêutica proporciona uma força anterior constante na maxila6.

Essa técnica propicia o tracionamento da maxila anteriormente e o redirecionamento da mandíbula em sentido horário, para baixo e para trás. Entretanto, essa terapêutica não é indicada para pacientes de face longa, com mordida aberta, visto que a rotação mandibular pode agravar o problema e levar à necessidade de correção cirúrgica6.

Entretanto, a técnica apresenta limitações, como, por exemplo, a baixa aceitação pelos pacientes em virtude das proporções do aparelho, uso intensivo diário (12/16h por dia), limitado avanço maxilar, alto risco de recidivas e possíveis complicações na articulação temporomandibular'?

Para casos em que há associação de retrusão maxilar e estreitamento da maxila, o tratamento precoce por meio da tração reversa é o mais indicado, sendo que dispositivos de expansão maxilar são utilizados como adjuntos, uma vez que permitem a correção da deficiência transversa, da mordida cruzada posterior, do aumento do comprimento do arco, além de favorecerem a movimentação da maxila para baixo e para frente em razão da disjunção das suturas maxilares?.

O objetivo deste estudo é analisar e discutir fatores determinantes para o planejamento da expansão maxilar.

\section{MÉTODOS}

O delineamento metodológico aplicado para a realização deste estudo foi uma revisão da literatura. Para a busca dos artigos científicos utilizou-se a base de dados SCIELO e LILACS. As palavras-chave utilizadas foram: Máscara Facial, Ortodontia; más oclusões da Classe III de Angle, expansão rápida da maxila, disjunção palatina, máscara facial.

Os critérios inclusivos foram: artigos publicados na Língua Portuguesa e Inglesa.

Todos os artigos foram avaliados em três etapas: primeiramente pelo título, caso fosse condizente com o tema, e depois o resumo; passando por essas duas etapas foi feita a leitura na íntegra do artigo.

\section{REVISÃO DA LITERATURA}

A correção precoce da má oclusão de Classe III permanece um desafio complexo e as abordagens interceptativas incluem aparelhos fixos, removíveis, aparelhos funcionais removíveis, mentoneira, máscara facial e sistemas de ancoragem esquelética ${ }^{8}$. 
SUASSUNA KML, SANTOS DCL, NEGRETE D, FLAIBAN E, SANTOS RL, BORTOLIN R. Expansão e disjunção palatina em pacientes classe iii com uso de máscara facial. Rev. Odontol. Univ. Cid. São Paulo 2018 jul/set 30(3) 290-303

ISSN 1983-5183

É importante mencionar que a má oclusão Classe III é caracterizada como uma discrepância dentária anteroposterior que pode ou não estar acompanhada por alterações esqueléticas. $O$ aspecto facial fica bastante comprometido nos casos onde existe envolvimento esquelético. O diagnóstico ideal da má oclusão de Classe III deve ser precoce, se possível ainda na dentição decídua. Quanto mais precoce, a intercepção suscita maiores efeitos ortopédicos em detrimento dos inevitáveis efeitos ortodônticos ${ }^{9}, 10$.

A expansão rápida da maxila (ERM) ou disjunção palatina é um tipo de intervenção ortopédica que possui grande utilidade terapêutica e que se tornou uma rotina na prática ortodôntica devido à sua aplicação em diversas situações clínicas".

Portanto, o fechamento da sutura palatina mediana é determinante em situações de insucesso na terapêutica da disjunção palatina ${ }^{12}$.

Em indivíduos com deficiência maxilar onde a mandíbula não é marcadamente afetada, o tratamento deve envolver a estimulação e direcionamento do crescimento maxilar por forças ortopédicas ${ }^{13}$.

O objetivo do tratamento ortopédico deve ser corrigir desequilíbrios funcionais, dentoalveolares, esqueléticos existentes e em desenvolvimento, os quais poderiam ajudar a minimizar a possibilidade de tratamento ortodôntico mais complicado envolvendo a extração de dentes permanentes e cirurgia ortognática ${ }^{14}$.

Por outro lado, ainda parece não existir consenso do momento do tratamento, precoce ou tardio, sendo o sucesso do tratamento precoce dependente do crescimento do esqueleto facial e da modificação deste $^{13 .}$

A terapia precoce com expansão rápida da maxila e protração maxilar tem sido indicada para tratar a maxila retruída pela aceleração do crescimento maxilar, cujo objetivo é focado em fornecer um ambiente mais favorável para o crescimento normal e em melhorar o desenvolvimento psicossocial da criança, desta forma limitado às dentaduras decídua e mista ${ }^{15}$.

A idade e a maturação esquelética avançada tornam o prognóstico pobre, o que está diretamente relacionado ao grau do efeito ortopédico. Em idades precoces, durante o período das dentaduras decídua, mista e permanente jovem, esse tratamento possui grande efeito ortopédico, quando comparado à dentadura permanente adulta, pois a resposta sutural e esquelética é mais favorável durante o período de crescimento. Em adultos, o aumento da dimensão esquelética transversa do palato promovido pela ERM é pequeno, sendo predominantemente dentoalveolar. Assim, a separação entre os incisivos centrais, sinal clínico de abertura da sutura palatina mediana, raramente ocorre. Portanto, para muitos autores, o período durante o surto de crescimento ou até os 15 anos de idade é considerado ideal para a realização da expansão rápida da maxila ${ }^{16}$.

O crescimento transverso do palato pela atividade osteogênica da sutura palatina mediana continua até a idade de 16 anos nas meninas e 18 anos nos meninos. No entanto, o grau de sinostose da sutura palatina mediana possui grande variabilidade individual. Em uma avaliação de autópsias humanas, foi encontrado um indivíduo de 27 anos sem nenhum grau de obliteração da sutura palatina mediana. Entretanto, sabe-se que existe relação entre o aumento da maturação esquelética e a obliteração da sutura palatina mediana. Por isso, historicamente, a interdigitação da sutura palatina mediana foi responsabilizada pela resistência à expansão palatal ${ }^{16}$. 
SUASSUNA KML, SANTOS DCL, NEGRETE D, FLAIBAN E, SANTOS RL, BORTOLIN R. Expansão e disjunção palatina em pacientes classe iii com uso de máscara facial. Rev. Odontol. Univ. Cid. São Paulo 2018 jul/set 30(3) 290-303

ISSN 1983-5183

Entretanto, estudos têm demonstrado que a maior resistência à ERM é representada pelo aumento da maturação esquelética dos ossos adjacentes, especialmente o osso zigomático, pela maior interdigitação de algumas suturas craniofaciais, principalmente as temporozigomática, frontozigomática, zigomatomaxilar e o osso esfenoide, pelo aumento da interdigitação da sutura pterigomaxilar ${ }^{16}$.

A determinação do grau de maturação esquelética, por meio da análise das radiografias de punho e mão, é de grande importância no diagnóstico e plano de tratamento das más oclusões esqueléticas, pois, dentre as idades biológicas (idades cronológica, esquelética, morfológica, dentária e circumpuberal), a idade esquelética representa com mais fidelidade o desenvolvimento somático geral do indivíduo ${ }^{16}$.

AERM em pacientes após a fase de crescimento está indicada para pacientes com até aproximadamente 30 anos de idade, com boa saúde periodontal e com necessidade, no máximo, de expansão moderada da maxila ao nível ósseo, e que aceitem um provável desconforto inerente ao processo $0^{17}$.

Muitos artigos discutem a indicação da expansão rápida da maxila previamente à prostraçãa ${ }^{18}$.

A expansão maxilar prévia produz um movimento da maxila para frente e para baixo afetando as suturas intermaxilares e a ruptura dessas suturas parece permitir uma reação mais positiva das forças de prostração ${ }^{19}$.

Parece haver menos compressão e mais tensão na área das suturas ao redor da maxila e no arco zigomático quando a sutura palatina é aberta, assim como uma diminuição da rotação para cima e para frente da maxila e do arco zigomático e também um maior deslocamento nas direções frontal, vertical e lateral' ${ }^{19}$.

Os efeitos da expansão não estão relacionados apenas à maxila, já que esta se relaciona com outros 10 ossos do esqueleto craniofacial, os quais são direta ou indiretamente influenciados pela expansão ${ }^{20}$.

Portanto, a sutura em idades mais precoces seria mais larga e maleável, tornando-se mais escamosa e sobreposta em idades mais tardias ${ }^{21}$.

A disjunção rápida da sutura palatina mediana restabelece as dimensões transversais da maxila e seu correspondente arco dentário, mediante a abertura da sutura palatina mediana associada às reações ortopédicas em outras suturas faciais e a uma pequena movimentação dos dentes póstero-superiores. Portanto, o procedimento ortopédico de ERM visa corrigir as atresias do arco dentário superior, sendo considerado um método eficiente e permanente na correção da deficiência transversal da maxila ${ }^{22}$.

Muitos trabalhos foram publicados evidenciando os efeitos ortopédicos e ortodônticos da ERM e mostraram que, além da separação da sutura palatina mediana, ocorre um aumento na largura do arco superior, avanço do ponto, movimento maxilar para baixo e para frente, inclinação alveolar e extrusão dentária, aumento do ângulo do plano mandibular, rotação horária da mandíbula e aumento da dimensão vertical inferior da face. Porém, em pacientes adultos, por causa da maior calcificação e rigidez das suturas, os efeitos observados são dentoalveolares e não esqueléticos ${ }^{17}$.

Vários aparelhos ortodônticos com parafuso disjuntor foram recomendados para ERM na literatura pesquisada, como o tipo Haas, Haas modificado, Hyxar, Hyrax modificado e o aparelho disjuntor com recobrimento oclusal preconizado por Mcnamara. Torna-se importante selecionar um aparelho disjuntor adequado para ERM, considerando o tipo de dentadura, idade do paciente e padrão de crescimento facial. 
ISSN 1983-5183

Dois tipos de expansores palatinos são amplamente reconhecidos na literatura, dento-muco-suportado (tipo Haas) e dento-suportado (tipo Hyrax), não havendo consenso quanto ao tipo de apoio que esse aparelho deve apresentar para causar maiores efeitos ortopédicos e menor desconforto aos pacientes ${ }^{23}$.

Há controvérsias quanto ao emprego dos tipos de aparelhos para a realização da ERM. O tipo de aparelho não é uma preferência do profissional, mas é determinado pelas necessidades e idades dentária e biológica do paciente. Diversos tipos e desenhos são apresentados na literatura, contudo, todos se constituem basicamente de um parafuso expansor colocado transversalmente à abóbada palatina, diferindo somente quanto ao tipo de ancoragem utilizada ${ }^{24}$.

A quantidade de expansão varia de acordo com as exigências individuais, sendo necessária uma sobrecorreção, devido aos efeitos de recidiva das inclinações dentárias posteriores. $O$ período de contenção pós-expansão deve ser feito com o próprio aparelho disjuntor por um período de três meses, e deve ser realizada uma radiografia oclusal para verificar a neoformação óssea e a remodelação da sutura antes da remoção do aparelho. Concluída essa fase, uma placa de contenção removível deve ser instalada e mantida por aproximadamente seis meses ${ }^{25}$.

A ERM (expansão rápida da maxila) junto à máscara facial reversa (MFR) leva a alterações esqueléticas e dentárias significativas em ambas as bases ósseas e permite resolução rápida da má oclusão de Classe III em indivíduos jovens ${ }^{26,27,28}$.

Um dispositivo denominado de Máscara Facial de Petit, com apoio na região de osso frontal e na região do mento, fornece maior ancoragem à correção oclusopatia Padrão III e aos problemas de ordem esquelética e/ou dental ${ }^{29}$.

A máscara facial de Petit possui um fio de aço localizado na linha média da face, com duas almofadas unidas por esse fio e um fio horizontal no centro, onde serão presos os elásticos para realizar a protração da maxila. Ela está indicada para casos de retrusão maxilar e pós-cirurgias. Suas vantagens são, por serem préfabricadas e simples, terem mais aceitação pelo paciente. Suas desvantagens são seu comprometimento estético e a possibilidade de o paciente ficar estrábico, devido ao fio de aço vertical ${ }^{30}$.

Assim, uma das alternativas de tratamento para Classe III é recorrer à ERM, seguido de Protração maxilar, com Máscara Facial, o que poderia influenciar positivamente a ação sobre as suturas circummaxilares, pela ação da força ortopédica, favorecendo a mecânica de tração reversa e o posicionamento anterior da maxila ${ }^{31}$.

Vários autores concordam que a máscara facial é eficaz na indução de crescimento da maxila em pacientes com deficiência maxilar e que pode atingir de 1,3 a 3mm de protração em 1 ano 32,33 .

A tração ortopédica com a máscara é aplicada na maxila com intuito de produzir o deslocamento da face média para anterior, a direção da força é determinada pela inclinação dos planos oclusal e mandibular, durante a tração ortopédica, são obtidos a coordenação do arco e o posicionamento individual do dente ${ }^{34}$.

Apesar de também produzir resultados positivos na dentição tardia e permanente jovem, a intervenção numa idade jovem promove melhor resposta ortopédica, pois o crescimento se normaliza após a terapia com a MFR ${ }^{35}$.

Há muito tempo é utilizada como protocolo no tratamento de pacientes com má oclusão de Classe III, 
SUASSUNA KML, SANTOS DCL, NEGRETE D, FLAIBAN E, SANTOS RL, BORTOLIN R. Expansão e disjunção palatina em pacientes classe iii com uso de máscara facial. Rev. Odontol. Univ. Cid. São Paulo 2018 jul/set 30(3) 290-303

ISSN 1983-5183

pois com a abertura da sutura maxilar ocorre a desarticulação das suturas circum-maxilares, o que favorece os efeitos da protração da maxila ${ }^{36}$.

A expansão maxilar foi defendida como uma importante parte da terapia de protração maxilar com máscara facial, pois é facilmente realizada no paciente em crescimento e propiciaria o movimento do ponto A para baixo e para frente e rotação da mandíbula para baixo e para trás, além de desarticular as suturas circum-maxilares. Essa desarticulação é postulada como a principal causa do efeito ortopédico alcançado com essa intervenção ${ }^{37}$.

O deslocamento anteroinferior da maxila, assim como a rotação horária da mandíbula, tendem a fazer com que haja um aumento na altura facial, efeito este que, para alguns autores, contraindicaria esse procedimento em pacientes hiperdivergentes ou com tendência para face longa ${ }^{38,39,40}$.

Com relação às alterações dentárias, observou-se que os vetores de força gerados pelos elásticos de tração, junto com o deslocamento mesial da maxila, fazem com que haja a tendência de os dentes posteriores superiores mesializarem e consequentemente projetarem os anteriores para vestibular ${ }^{41}$.

A rotação para trás da mandíbula, junto com a ancoragem mentoniana do aparelho tende a restringir o deslocamento anterior dos incisivos inferiores ou até mesmo provocar uma pequena verticalização ou lingualização desses dentes ${ }^{8}$.

A expansão rápida da maxila, prévia à protração maxilar, é vista por alguns autores como um procedimento que não deve ser utilizado de forma indiscriminada e sim apenas em casos onde realmente é necessária a abertura da sutura palatina mediana, uma vez que, para esses autores, o procedimento de expansão não altera de forma significativa a efetividade da mecânica ${ }^{42} \mathrm{Em}$ um caso clínico, indicaram a ERM com aparelho tipo Haas e máscara facial, num paciente com idade de 7 anos e 8 meses de idade, em fase de dentadura mista, do gênero masculino, com diagnóstico de má oclusão Classe III. O aparelho disjuntor tipo Haas foi ativado duas vezes ao dia. Após o parafuso estabilizado iniciou-se a protração da maxila com a máscara facial (uso de 14 horas por dia). Então, o expansor foi removido e colocado uma placa maxilar de acrílico para contenção do tratamento. Os autores concluíram que a ERM associada à máscara facial é bastante eficaz no tratamento da má oclusão de Classe III em idade precoce ${ }^{11}$.

Em outro estudo foram avaliados e comparados dois grupos de pacientes portadores de má oclusão Classe III, submetidos a diferentes protocolos de ERM, seguidos de protração maxilar, utilizando-se aparelho Hyrax e máscara facial tipo Petit e elásticos calibrados em $500 \mathrm{~g}$ de força para cada lado e orientados em $30^{\circ}$ abaixo do plano oclusal, com uso diário de 14 horas. Os resultados foram semelhantes para ambos os grupos. A maxila deslocou-se para frente e para baixo, com rotação horária do plano palatal no G1 e rotação anti-horária no G2. Não foram verificadas alterações mandibulares. Apenas para o G2 foi verificado aumento da altura facial inferior e extrusão dos molares superiores. A autora concluiu que houve melhora do perfil mole dos pacientes, tornando-os mais convexos, com projeção dos tecidos moles do terço médio da face, em ambos os grupos ${ }^{43}$.

A terapia da máscara facial foi combinada com a de expansão maxilar em virtude da presença de maxila estreita, acarretando mordida cruzada posterior. Quando aparecem no diagnóstico deficiência das bases ósseas, maxila retraída, independentemente da presença de mordida cruzada, é indicada a colocação de um aparelho expansor com a intenção de estimular os sítios de crescimento, suturas, como, por exemplo, frontomaxilar, nasomaxilar e zigomático-maxilar. A disjunção das suturas facilita o trabalho ortopédico, com 
ISSN 1983-5183

o crescimento normal da maxila, que tem um deslocamento para baixo e para frente. Com a utilização da máscara de Petit, apontando-se um ponto na fronte e outro no mento para tracionar a maxila na sua direção de crescimento para baixo e para frente, aplicou-se uma força ortopédica de $200 \mathrm{~g}$ de cada lado, capaz de induzir o crescimento ósseo. Essa força foi aplicada durante nove meses a um ano, tempo necessário para crescer e ter estabilidade óssea. Portanto, o tracionamento da maxila por meio da terapia da tração reversa com máscara facial, associado à expansão maxilar, resultou em benefícios para a correção das deficiências maxilares transversais e características da Classe III'.

Embora o aparelho expansor de Haas não tenha capacidade de deslocar a maxila anteriormente, ele é uma opção na associação com a máscara de protração, com a intenção de deslocamento anterior da face média. Essa opção é justificada pelo fator biológico, representado pela indução de alteração celular nas suturas circum-maxilares com a disjunção palatina ${ }^{44}$.

A eficácia dessa terapia depende também do controle dos movimentos ortodônticos indesejáveis, além da colaboração e do uso pelo paciente. É essencial levar em consideração fatores como o potencial de crescimento e a direção de crescimento, que podem influenciar no sucesso do tratamento ${ }^{28}$.

A força aplicada e a quantidade de horas de uso são um tema também controverso na literatura, pois existe um número grande de combinações entre a magnitude da força e o tempo de utilização do dispositivo. No entanto, na literatura observa-se que a protração maxilar geralmente requer uma força de 300 a $600 \mathrm{~g} / \mathrm{f}$ por lado, dependendo da idade do paciente ${ }^{45}$.

E um caso clínico foi realizado o tratamento da má oclusão de Classe III, na fase de dentadura mista, devido a uma deficiência de crescimento anteroposterior da maxila. 0 tratamento foi realizado com expansão rápida da maxila, utilizando-se um disjuntor de Haas com ativação de um quarto de volta por dia, durante quinze dias, associado à tração reversa da maxila, por meio de uma máscara facial com 500g de cada lado por aproximadamente 12 meses. Os traçados cefalométricos inicial e pós-tratamento confirmam o bom resultado promovido pelo tratamento ${ }^{46}$.

O tempo de uso diário do aparelho, preconizado pelos autores, variou na média de 10 a 17 horas (ISCI, SANCHEZ, PROFITT), a força de tração dos elásticos entre 600 e $800 \mathrm{~g}$ de cada lado com direção para frente e para baixo (RODRIGUES e CEVIDANES) e o tempo total da mecânica ficaram na média de 6 a 12 meses (RODRIGUES e CAKIRER), sendo que os menores períodos foram observados nos pacientes mais colaboradores em relação ao tratamento proposto $39,40,47,48,49$.

Em uma revisão sistemática realizada, pode-se observar nos artigos consultados uma magnitude de força variável aplicada, sendo a mínima entre $180 \mathrm{~g}$ e $250 \mathrm{~g}$ até a intensidade de $800 \mathrm{~g}$. Já para a duração diária de uso do dispositivo os valores variam de 12 horas/dia a 16 horas/dia ${ }^{50}$.

A necessidade de sobrecorreção do trespasse horizontal é sempre bem-vinda, na tentativa de prevenir a retração da maxila e compensar o crescimento mandibular. A sobrecorreção é conseguida com a utilização 10 horas de máscara de protração maxilar durante 3 a 5 meses, e pode ter como resultado um trespasse horizontal de 4 a $5 \mathrm{~mm}$. O tempo de tratamento médio é de 6 meses a 1 ano. As chances de sucesso dependerão da relação entre a maxila e mandíbula, a relação dos maxilares com o crânio e a dimensão vertical e a idade do paciente ${ }^{29,48}$.

No protocolo de tratamento da expansão rápida da maxila associada à tração maxilar, o paciente retorna a cada 6 meses, para monitoramento de crescimento e controle de irrupção, intervalo de tempo 
ISSN 1983-5183

que pode ser reduzido, caso aconteçam problemas com a irrupção. Se a face for no mínimo aceitável e se a oclusopatia tiver uma magnitude possível de ser corrigida ortodonticamente, um tratamento compensatório será indicado. Se a face for desagradável, o tratamento cirúrgico será indicado ${ }^{50}$.

Portanto, são de suma importância a individualização do pico de crescimento e a avaliação biológica da maturidade esquelética na determinação do diagnóstico, bem como o planejamento individualizado para indivíduos com má oclusão de Classe III28.

\section{DISCUSSÃO}

Discute-se aqui a efetividade do tratamento das más oclusões de Classe III de Angle com o uso da expansão e disjunção palatina associado à máscara facial.

A correção precoce da má oclusão de Classe III permanece um desafio complexo, e as abordagens interceptativas da máscara facial e sistemas de ancoragem esquelética ${ }^{8}$.

Alguns autores mencionam que a expansão rápida da maxila (ERM) ou disjunção palatina é um tipo de intervenção ortopédica com grande utilidade terapêutica. ${ }^{9}$ Mostraram que, além da separação da sutura palatina mediana, ocorre um aumento na largura do arco superior, avanço do ponto, movimento maxilar para baixo e para frente, inclinação alveolar e extrusão dentária, aumento do ângulo do plano mandibular, rotação horária da mandíbula e aumento da dimensão vertical inferior da face. Porém, em pacientes adultos, por causa da maior calcificação e rigidez das suturas, os efeitos observados são dentoalveolares e não esqueléticos ${ }^{17}$.

O tratamento deve ser iniciado o mais precocemente possível e, embora a dentadura mista precoce, assim como a tardia, sejam um período ótimo de tratamento ortopédico da desarmonia maxilar e se obtenha sucesso em ambas, se feito no início da dentadura mista tem-se melhores resultados do que quando iniciado na dentadura mista tardia $13,16,17,21,22$.

Uma expressiva maioria dos autores preconiza primeiramente o uso apenas do disjuntor para, imediatamente após o término das ativações deste, instalar a máscara de protração maxilar. 0 aparelho do tipo dento-muco-suportado de Haas teve a preferência da maioria dos autores ${ }^{23}$.

Numa ativação igual a um quarto de volta, a maioria dos autores preferiu ativar o disjuntor maxilar ortopédico 2 vezes ao dia, sendo preconizada a abertura inicial do parafuso expansor até que se verifique o rompimento da sutura palatina mediana"1.

Quanto à magnitude da força ortopédica da máscara de protração maxilar, embora os maiores valores encontrados neste estudo tenham sido de $200 \mathrm{~g}^{1}$ a $500 \mathrm{~g}^{25}$ de cada lado, a maioria dos autores mantém como rotina a magnitude de força ortopédica entre $300 \mathrm{~g}$ e $600 \mathrm{~g}$ de cada lado. ${ }^{27}$ Já alguns autores adotam um período mínimo de uso (abrangendo todo o período noturno) da máscara de protração maxilar de 12 a 16 horas $^{11,50}$.

O movimento da maxila para frente e para baixo, ou seja, com uma rotação anti-horária, é o mais comum, devendo ser ressaltado que nessa rotação anti-horária encontramos a maxila posterior mais baixa do que a anterior. Há também uma incidência considerável de movimento anterior sem rotação e, nesses casos, a anteriorização é proporcionalmente maior quanto mais precoce se iniciar a terapia, devido à liberação da sutura pterigomaxilar ${ }^{18}$. 
ISSN 1983-5183

O conjunto dentoalveolar superior move-se com o maxilar superior e sofre uma translação anterior, com os molares sendo mesializados e os anteriores superiores podem ser minimizados se os dentes superiores forem estabilizados, para se conseguir uma maximização do efeito ortopédico e minimização do efeito ortodôntico ${ }^{16,17}$.

O movimento mandibular após a terapia associada é geralmente representado por uma rotação horária, que expressa uma inibição do crescimento horizontal da mandíbula auxiliada, também, pelo crescimento ântero-superior do côndilo, o qual acarreta uma diminuição do comprimento mandibular total ${ }^{17}$.

No movimento dentoalveolar inferior, após a terapia associada, ocorre geralmente uma retrusão ou lingualização dos anteriores inferiores, podendo ocorrer também o movimento para trás e para baixo, ou ainda se manterem estáveis ${ }^{17,21}$.

A sobrecorreção do trespasse horizontal nos casos de Classe Ill de Angle com componente esquelético é sempre bem-vinda, servindo na tentativa de prevenir a retração maxilar e compensar o crescimento mandibular. Além de ser importante para a manutenção do sucesso da correção, é reconhecidamente necessária por diversos autores. Consegue-se a sobrecorreção utilizando-se $12 \mathrm{~h}$ a $14 \mathrm{~h}$ de máscara de protração maxilar e a duração do tempo de sobrecorreção gira em torno de 3 meses; assim, a prática da sobrecorreção é aconselhável para compensar o crescimento deficiente da maxila. ${ }^{25}$.

Vários autores relataram sucesso em um período de tratamento de até 6 meses, enquanto outros conseguiram êxito em um período médio de tratamento compreendido entre 6 meses e 1 ano, e ainda outros conseguiram resultados positivos apenas em períodos de tratamento mais prolongados, de 1 a 2 anos.

Dentre os fatores que podem contribuir para a recidiva de uma Classe Ill esquelética está uma postura baixa da língua, que não tenha sido bem resolvida, assim como igualmente importante para se evitarem recidivas é a não remoção completa e imediata das forças após a sobrecorreção, o que deve ser feito pela suspensão progressiva das horas de uso da máscara de protração ${ }^{25}$.

O tratamento é considerado eficiente e estável diante dos resultados de sucesso obtidos, devendo ser monitorado, por meio de avaliações trimestrais ${ }^{1,9,22}$.

\section{CONCLUSÃO}

Quando a má oclusão de Classe III for determinada por uma retrusão maxilar, o tratamento ortopédico precoce é indicado, havendo grandes possibilidades de ser um tratamento definitivo. Nesses casos, o tratamento de escolha é a disjunção palatina seguida do uso de um aparelho de tração reversa da maxila (máscaras faciais).

De acordo com o objetivo proposto, os fatores determinantes para o planejamento da expansão maxilar dependerão do tempo do tratamento para se conseguirem resultados positivos, pois variam muito, de acordo com as características da força empregada, tais como magnitude, direção e horas de uso, e as chances de sucesso dependem de alguns fatores, tais como: a relação entre a maxila e a mandíbula, a relação dos maxilares com o crânio, a dimensão vertical e a idade do paciente. 
ISSN 1983-5183

\section{REFERÊNCIAS}

1. PRIMO BT, Eidt SV, Gregianin JA, Primo NA, Faraco Junior IM. Terapia da tração reversa maxilar com máscara facial de Petit - relato de caso. RFO UPF 2010 ago.;15(2):171-6.

2. PITHON MM, Bernardes LAA. Tratamento da má oclusão Classe III esquelética através de expansão rápida da maxila associada à exodontia de pré-molares inferiores: relato de caso clínico. Rev clín ortodon Dental Press 2008 jun.-jul.;7(3):72-82.

3. CAPELOZZA Filho L. Diagnóstico em ortodontia. Maringá: Dental Press; 2004.

4. BEZERRA JO, Silva AM, Peixoto MGS, Tiago CM. Tratamento da má oclusão de classe III por meio de disjunção maxilar e tração reversa da maxila: relato de caso. J Odontol FACIT 2014 1(1):32-9.

5. DILIO RC, Micheletti KR, Cuoghi OA, Bertoz APM. Tratamento compensatório da má oclusão de classe III: revisão de literatura. Arch Health Invest 2014 3(3):84-93.

6. ARAÚJO EA, Araújo CV. Abordagem clínica não-cirúrgica no tratamento da má oclusão de Classe III. Rev Dent Press Ortodon Ortop Facial 2008 dez.;13(6):128-57.

7. FARRONATO G, Giannini L, Galbiati G, Maspero C. Sagittal and vertical effects of rapid maxillary expansion in Class I, II, and III occlusions. The Angle orthodontist 2011 Mar;81(2):298-303.

8. SEEHRA J, Fleming PS, Mandall N, Dibiase AT. A comparison of two different techniques for early correction of Class III malocclusion. The Angle orthodontist 2012 Jan;82(1):96101.

9. OLTRAMARI PVP, Garib DG, Conti ACCF, Henriques JFC, Freitas MR. Tratamento ortopédico da Classe III em padrões faciais distintas. Rev Dent Press Ortodon Ortop Facial 2005 out.;10(5):72-82.

10. SOUSA MCN, Gonçalves MA, Pinheiro PMM. Má oclusão Classe III de Angle: diagnóstico e tratamento precoce. Rev Científica ITPAC 2010 3(2):28-39.

11. LIMA Filho RMA. Alterações na dimensão transversal pela expansão rápida da maxila. Rev Dent Press Ortodon Ortop Facial 2009 out.;14(5):146-57.

12. ALBUQUERQUE RR, Eto LF. Previsibilidade de sucesso na disjunção palatina avaliada pelo estágio de maturação esquelética: estudo piloto. Rev Dent Press Ortodon Ortop Facial 2006 abr.;11(2):74-83.

13. KAMA JD, Ozer T, Baran S. Orthodontic and orthopaedic changes associated with treatment in subjects with Class III malocclusions. European journal of orthodontics 2006 Oct;28(5):496-502.

14. YOSHIDA I, Yamaguchi N, Mizoguchi I. Prediction of post-treatment outcome after combined treatment with maxillary protraction and chincap appliances. European journal of orthodontics 2006 Feb;28(1):89-96. 
SUASSUNA KML, SANTOS DCL, NEGRETE D, FLAIBAN E, SANTOS RL, BORTOLIN R. Expansão e disjunção palatina em pacientes classe iii com uso de máscara facial. Rev. Odontol. Univ. Cid. São Paulo 2018 jul/set 30(3) 290-303

ISSN 1983-5183

15. KAPOOR P, Kharbanda OP. Correction of skeletal class III in a growing male patient by reverse pull facemask. Journal of the Indian Society of Pedodontics and Preventive Dentistry 2011 Jul-Sep;29(3):273-7.

16. ROSSI RRP, Araújo MT, Bolognese AM. Expansão maxilar em adultos e adolescentes com maturação esquelética avançada. Rev Dent Press Ortodon Ortop Facial 2009 out.;14(5):43-52.

17. CAPELOZZA Filho L, Silva Filho OG. Expansão rápida da maxila: considerações gerais e aplicação clínica: parte II. Rev Dental Press Ortodon Ortop Facial 1997 maio/jun. ;29(4):88-101.

18. KILIC N, Catal G, Kiki A, Oktay H. Soft tissue profile changes following maxillary protraction in Class III subjects. European journal of orthodontics 2010 Aug;32(4):419-24.

19. YU HS, Baik HS, Sung SJ, Kim KD, Cho YS. Three-dimensional finite-element analysis of maxillary protraction with and without rapid palatal expansion. European journal of orthodontics 2007 Apr;29(2):118-25.

20. GODT A, Zeyher C, Schatz-Maier D, Goz G. Early treatment to correct Class III relations with or without face masks. The Angle orthodontist 2008 Jan;78(1):44-9.

21. SILVA Filho OG, Graziani GF, Lauris RCMC, Lara TS. Ossificação da sutura palatina mediana após o procedimento de expansão rápida da maxila: estudo radiográfico. Rev Dent Press Ortodon Ortop Facial 2008 abr.;13(2):124-31.

22. SCANAVINI MA, Reis SAB, Simões MM, Gonçalves RAR. Avaliação comparativa dos efeitos maxilares da expansão rápida da maxila com os aparelhos de Haas e Hyrax. Rev Dent Press Ortodon Ortop Facial 2006 fev.;11(1):60-71.

23. GARIB DG, Henriques JF, Janson G, Freitas MR, Coelho RA. Rapid maxillary expansion--tooth tissue-borne versus tooth-borne expanders: a computed tomography evaluation of dentoskeletal effects. The Angle orthodontist 2005 Jul;75(4):548-57.

24. PENHAVEL RA, Souza HA, Patel MP, Freitas KMS, Cançado RH, Valarelli FP. Tratamento da má oclusão de classe III com a máscara facial. Rev Uningá 2013 out.-dez.;38(1):107-20.

25. MARTINS MCF, Costa C, Abrão J, Borri ML. Expansão rápida da maxila: análise da densidade radiográfica da sutura palatina mediana e sua correlação nos estágios de neoformação óssea, por meio de imagem digitalizada. Rev Dent Press Ortodon Ortop Facial 2009 out.;14(5):38e1-e9.

26. MOSCARDINI MS. A protração maxilar nos tratamentos precoces da Classe III esquelética. Rev clín ortodon Dental Press 2006 dez.-jan.;4(6):72-82.

27. MOREIRA AKA, Fuziy A, Tukasan PC, Moreira Filho VA. Descrição do aparelho Moreira: proposta de tratamento da má oclusão classe III de Angle. Revista Clin Ortodon Dental Press 2007 6(5):31-41.

28. ANTUNES CF, Camarote EA, Quaggio ÂM, Bigliazzi R, Ortolani CLF, Faltin Jr. K. Alterações dentárias decorrentes da expansão rápida da maxila e máscara facial reversa. Braz Dent Sci 2010 jul.-dez.;13(6):36-41. 
ISSN 1983-5183

29. ANTONIAZZI SP. Alterações faciais decorrentes do tratamento da má oclusão de classe III, com deficiência de maxila, empregando disjunção maxilar e tração reversa [Dissertação]. Santa Maria: Universidade Federal de Santa Maria; 2011.

30. YAVUZ I, Halicioglu K, Ceylan I. Face mask therapy effects in two skeletal maturation groups of female subjects with skeletal Class III malocclusions. The Angle orthodontist 2009 Sep;79(5):842-8.

31. KIRCELLI BH, Pektas ZO. Midfacial protraction with skeletally anchored face mask therapy: a novel approach and preliminary results. American journal of orthodontics and dentofacial orthopedics : official publication of the American Association of Orthodontists, its constituent societies, and the American Board of Orthodontics 2008 Mar;133(3):440-9.

32. MIGUEL JAM, Gava E. Tratamento da classe III: novas perspectivas para um antigo desafio: nova visão em ortodontia e ortopedia funcional dos maxilares. São Paulo: Santos; 2010.

33. BACCETTI T, Franchi L, Mcnamara JA. Growth in the untreated class III subject. Seminars Orthodontics 2007 set.;13(3):130-42.

34. VALDRIGHI H, Vedovello SAS, Lucato A, Tubel CAM. Diagnóstico, prognóstico e tratamento da má oclusão de classe III: nova visão em ortodontia e ortopedia funcional dos maxilares. São Paulo: Santos; 2010.

35. TABUCHI MKO. Estudo das alterações dento-esqueléticas da maxila após terapia de expansão rápida e máscara facial, em casos de classe III esquelética [Monografia]. São Paulo: Universidade Paulista-UNIP; 2004.

36. NGAN P. Peter Ngan: entrevista. Rev Dent Press Ortodon Ortop Facial 2008 fev.;13(1):2433.

37. VAUGHN GA, Mason B, Moon HB, Turley PK. The effects of maxillary protraction therapy with or without rapid palatal expansion: a prospective, randomized clinical trial. American journal of orthodontics and dentofacial orthopedics: official publication of the American Association of Orthodontists, its constituent societies, and the American Board of Orthodontics 2005 Sep;128(3):299-309.

38. VEDOVELLO SAS, Valdrighi H, Manhães FR, Vedovello Filho M, Santamaria Junior M. Tratamento precoce da má oclusão de classe III com máscara de protração maxilar associada a elastic intrabucal. Rev Clin Ortod Dental Press 2012 jun.-jul.;11(3):90-7.

39. SILVA Filho OG, Queiroz APC, Herkrath FJ, Silva GFB. Correlação entre padrão facial e relação sagital entre os arcos dentários no estágio de dentadura decídua: considerações epidemiológicas. Rev Dent Press Ortodon Ortop Facial 2008 fev.;13(1):101-12.

40. PROFFIT WR. Ortodontia contemporânea. 4. ed. Rio de Janeiro: Elsevier 2007.

41. CEVIDANES L, Baccetti T, Franchi L, Mcnamara JA, Jr., De Clerck H. Comparison of two protocols for maxillary protraction: bone anchors versus face mask with rapid maxillary expansion. The Angle orthodontist 2010 Sep;80(5):799-806. 
ISSN 1983-5183

42. LEE DY, Kim ES, Lim YK, Ahn SJ. Skeletal changes of maxillary protraction without rapid maxillary expansion. The Angle orthodontist $2010 \mathrm{Jul} ; 80(4): 504-10$.

43. VECCHI A. Comparação da protração maxilar em pacientes portadores de maloclusão Classe III após dois protocolos de expansão rápida da maxila [Dissertação]. Porto Alegre: Pontifícia Universidade Católica do Rio Grande do Sul, Faculdade de Odontologia; 2008.

44. Lima EB, Bernardes LAA. Avaliação da sutura palatina mediana e das alterações verticais das bases ósseas pós-expansão rápida da maxila com aparelho tipo Haas. J Bras Ortodon Ortop Facial 2003 8(48):485-95.

45. LIOU EJ. Effective maxillary orthopedic protraction for growing Class III patients: a clinical application simulates distraction osteogenesis. Progress in orthodontics 2005 6(2):154-71.

46. KAGY V, Moro A. Tratamento da má-oclusão de classe III com disjunção palatina associada à tração reversa da maxila. Rev Dens 2008 16(2):63.

47. ISCI D, Turk T, Elekdag-Turk S. Activation-deactivation rapid palatal expansion and reverse headgear in Class III cases. European journal of orthodontics 2010 Dec;32(6):70615.

48. RODRIGUES LRL, Baddredine FR, Cappellette Jr. M, França NM. Protração maxilar associada à disjunção maxilar ortopédica. Rev Clín Ortodon Dental Press 2007 jun.-jul. ;6(3):48-56.

49. CAKIRER B, Kucukkeles N, Nevzatoglu S, Koldas T. Sagittal airway changes: rapid palatal expansion versus Le Fort I osteotomy during maxillary protraction. European journal of orthodontics 2012 Jun;34(3):381-9.

50. PERRONEI APR, Mucha JN. O tratamento da classe III - revisão sistemática: parte I: magnitude, direção e duração das forças na protração maxilar. Rev Dent Press Ortodon Ortop Facial 2009 out;14(5):109-17.

RECEBIDO EM 07/03/2018

ACEITO EM 28/09/2018 